\title{
What does empathy sound like in social work communication? A mixed-methods study of empathy in child protection social work practice.
}

\begin{abstract}
It is widely accepted that empathy is important for social work practice, yet there are multiple dimensions of empathy and comparatively few studies of empathy as a component of social work skill. To date published studies have been quantitative and as a result, we know little about how social workers demonstrate empathy in practice or what skilled empathic practice in child and family social work might sound like. This study contributes to the development of understanding of empathy as a social work skill through a mixed methods analysis of 110 audio recordings of meetings in a child protection service between workers and parents, applying a coding framework for analysis. Findings indicate that workers who demonstrate higher levels of empathy skill use more open questions and reflections in their communication with parents. Further, they demonstrate curiosity about and make efforts to understand parents' often difficult experiences, including a focus on emotions. That the majority of workers were found not to demonstrate a high level of empathy skill presents concerns to be considered by the social work profession. A deeper understanding of empathy presents an opportunity for an increased focus in organisations to enable workers to demonstrate empathy towards families they work with.
\end{abstract}

Key words: empathy, child protection, direct practice, social work communication

\section{Introduction}

It is widely accepted that empathy is an important skill in social work (Grant, 2014). Empathy is consistent with core social work values including respect for those we work with (Gerdes and Segal, 2009) and has an important role in developing the relationship between social workers and families (Forrester et al, 2008); relationships that are developed in the context of 'intense emotional experiences' of child protection social work (Ferguson, 2017 p.1011). Research suggests that service users want empathy from their social workers (Ingram, 2013) and in recent years there has been a renewed focus on relationship- based approaches within child and family social work (Ruch et al, 2017; Ingram and Smith, 2018). An overview report on a programme of innovation in child and family social work identified empathy as a core element of 'most models of good practice' (McNeish, 2017 p.4). There has been a growing emphasis within social work on outcomes and the development of evidence based interventions (Forrester, 2017), and exploration of the role of empathy within this has been the focus of a recent study (Forrester et al, in preparation).

Empathy is a complex concept with multiple definitions and conceptualisations including as a skill, trait or emotion ((Allen and Roberts, 2017). Studies of empathy within social work have adopted a range of methods depending on how empathy has been conceptualised including social worker self-report (Grant, 2014) and neurological examination (Gerdes and Segal, 2011).

To begin to unravel the complexity of empathy, it is helpful to conceptualise it as including three dimensions: emotional, cognitive and behavioural (Gerdes and Segal, 2011). Studies that have focused on empathy in the internal world of social workers include the work by Grant (2014) and Gerdes and Segal (2011). Grant (2014) explores how social workers can 
be supported to process the emotional elements of empathy while Gerdes and Segal (2011) focus on how empathy is experienced and processed neurologically.

Our study moves away from the internal world of the social worker and focuses on the behavioural dimension of empathy; we are concerned with how social workers communicate empathy to the families they are working with. Communication of empathy between professionals and service users has been the focus of recent studies in other settings, including between nurses and parents of children in hospital (Bry et al, 2016) and police officers and offenders(Dando and Oxburgh, 2016), using different approaches and definitions.

There is a less developed body of research on the behavioural dimension of empathy in social work practice. The empirical studies that have focussed on social work communication of empathy have been limited to quantitative approaches, and have only recently included studies of real examples of practice (Nerdrum, 1997; Forrester et al, 2008; Forrester et al, 2017; Forrester et al, 2018). As a result, despite the latest studies being close to social work practice, there is a gap in our understanding about how social workers demonstrate empathy, and we know little about what highly skilled empathic practice in child and family social work might sound like.

Within the latest body of quantitative studies, a predominant approach to researching empathy draws on Motivational Interviewing (MI). MI is a collaborative person-centred style of communication originating in substance misuse therapy (Rollnick and Miller, 1995), and is widely considered a good fit with social work values (Hohman, 2012). MI is regarded as part of the evidence base for social work (Hohman et al, 2015) and has been adopted by social work organisations as a practice model (Forrester et al, 2017, Luckock et al, 2017). This recent programme of research has operationalised the $\mathrm{Ml}$ framework, which has been used extensively elsewhere (Magill et al, 2018) to analyse and support the development of social worker communication skills. The Ml framework includes empathy as one of four core skills and its application results in a score on a five-point scale for each skill (Whittaker et al, 2016).

Our study builds on this programme of work by applying the MI definition of empathy 'the extent to which the clinician understands or makes an effort to grasp the client's perspective and feelings: literally, how much the clinician attempts to "try on" what the client feels or thinks' (Moyers et al, 2005) and coding method to analysing empathy in audio recordings of real social work practice. We extend the quantitative approach applied so far, to adopt a mixed methods approach, aiming to contribute to understanding of how social workers demonstrate empathy in practice and what this might sound like. Our research questions are:

What are the behavioural components of social worker communication of empathy?

What are the qualitative features of social worker communication of empathy?

\section{Method}

Data collection 
The study was part of an evaluation of a project funded by the Department for Education Children's Services Innovation Programme. The project was implemented by the children's services department of a local authority in England. It included several strands; including the introduction of $\mathrm{Ml}$ as a model to develop relationship-based practice, involving a three-day training course for workers. Research was conducted in 2015/6 and researchers were based alongside the social work teams within the child protection service.

The sample consisted of new cases allocated to a worker within the child protection teams during the period of data collection. All workers with a case allocated in the period were invited to participate. The worker invited a parent or carer of the allocated child to take part in the study. The researcher completed a questionnaire with the worker to provide context about the family, accompanied the worker to a visit with the family and audio-recorded the visit.

Seventy three workers took part; $49(67 \%)$ were social workers, $22(30 \%)$ were child practitioners (30\%) and $2(3 \%)$ were parent support workers (3\%). 65 social work practitioners were female and 8 were male. 26 social work practitioners participated with more than one family $($.

One hundred and ten families took part in the research. Half $(55 ; 50 \%)$ were families with a 'child in need'; over a third were families with a child on a child protection plan (38; 35\%), and $3(3 \%)$ were families with a 'looked after child'. The legal status of 14 families that took part in the research was unknown (13\%). The visits were with at least one parent or carer ( 'parent' is used as a summary term for all parents and carer participants).

\section{Ethics}

Ethical approval for the research was obtained from the authors'] university ethics committee. Family participation in the research was voluntary and anonymity was guaranteed to families and workers with the exception of any safeguarding concerns. Informed consent was obtained from all participants.

\section{Analysis}

There were three stages of analysis involving quantitative and qualitative methods.

\section{1) Quantitative coding of the audio recordings ( $n=110)$}

The recordings were coded (Whittaker et al, 2016), using a coding sheet and a score was given on a 5-point scale in line with the coding framework. The coder also categorised and annotated what the social worker said. This included four different types of questions and statements: open questions, closed questions, simple reflections (a reflective statement that only attends to the most recent utterance of the parent) and complex reflections (which add depth, emotion or meaning, usually by reflecting beyond the previous utterance). This analysis provided the score for empathy and behaviour count data.

\section{2) Quantitative analysis of coding sheets $(n=110)$}

Behaviours and behaviour counts were analysed to calculate five 'behaviour count variables': 
- number of open questions asked per minute of recording

- number of open questions as a per cent of the total number of questions asked

- number of complex reflections as a per cent of the total number of reflections offered

- total number of reflections offered per minute of recording,

- ratio of reflections offered to questions asked

Scores for each were calculated at an individual level and at an aggregate level to reflect an overall average at different levels of empathy skill.

\section{3) Qualitative analysis}

Coding sheets $(n=110)$

The coding sheets were grouped into three according to the level of empathy skill: low; mid and high. The qualitative coding sheet data included:

- the notes made by each coder as a commentary on the empathy score

- content within the four behaviour count categories: open questions; closed questions; simple reflections and complex reflections

A semantic 'bottom-up' thematic analysis approach was applied (Braun and Clark, 2006) to the qualitative coding sheet data for each of the three skill levels and themes and subthemes were identified.

Transcriptions $(n=10)$

A sample of ten recordings was transcribed, to include all of the recordings that scored 'high' and the same number of 'low' recordings. Analysis was extended to include not only what the worker said, but how the parent responded. Extracts from each of the transcriptions were selected to illustrate the content of interactions within each of the themes and sub-themes. For one of the themes identified, additional analysis of word count and number of speech turns was conducted. Names were changed and specific identifiable details were altered to protect anonymity.

\section{Results}

\section{Level of empathy skill demonstrated by workers}


Figure 1 Distribution of empathy scores

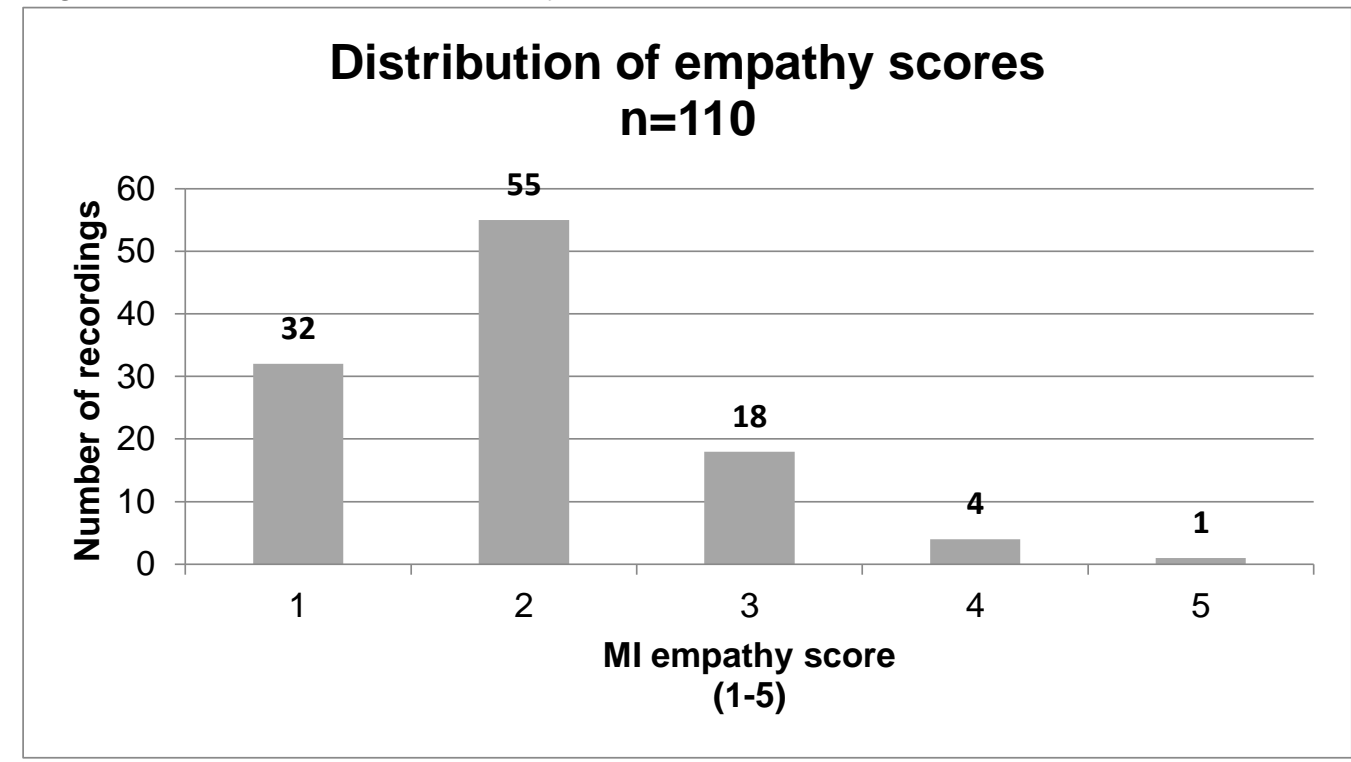

Figure 1 shows the distribution of empathy scores. The mean empathy score was 1.97. Around a third demonstrated the lowest skill level of one $(n=32 ; 29.1 \%)$ and half scored two $(n=55 ; 50.0 \%)$. The remaining one-fifth of recordings $(n=23 ; 20.9 \%)$ demonstrated a skill level of three or above: 18 (16.4\%) scored three, 4 (3.6\%) scored four and one (0.9\%) scored five.

For subsequent analyses, the scores were grouped to represent low $(n=87 ; 79.1 \%$; scores 1 and 2$)$, mid ( $n=18 ; 16.4 \%$; score 3 ) and high ( $n=5 ; 4.5 \%$; scores 4 and 5$)$ demonstration of empathy skill.

\section{The behaviours associated with different levels of empathy skill}

Initial analysis explored the presence and prevalence of the four key behaviours linked to coding for empathy skill: open questions, closed questions, simple reflections and complex reflections. Table 1 shows the range within the sample, at an individual recording level, for each of the behaviours, and the length of the interactions.

Table 1 Range in counts of behaviours and length of interaction

\begin{tabular}{|l|r|r|}
\hline Count of behaviours present & $\begin{array}{r}\text { Range of number of } \\
\text { behaviours present in } \\
\text { interactions } \\
(\mathbf{n}=110)\end{array}$ & $\begin{array}{r}\text { Mean number of } \\
\text { behaviours present in } \\
\text { interactions } \\
(\mathbf{n}=110)\end{array}$ \\
\hline Number of open questions & $0-33$ & 8.08 \\
\hline No. closed questions & $1-51$ & 14.05 \\
\hline No. simple reflections & $0-17$ & 2.70 \\
\hline No. complex reflections & $0-13$ & 0.66 \\
\hline Length of interaction & $16-88$ minutes & 37 minutes \\
\hline
\end{tabular}




\section{Behaviour variables}

The second stage of analysis analysed the behaviours, the length of interaction and skill level. Table 2 illustrates how the length of interaction and the mean score for each of the five behaviour variables increased as empathy skill level improved.

Table 2 Analysis of the behaviour variables by skill level

\begin{tabular}{|c|c|c|c|c|c|}
\hline & & Mean & SD & $F$ & Sig. \\
\hline \multirow{4}{*}{$\begin{array}{l}\text { Length of } \\
\text { recording }\end{array}$} & Low & 36.1034 & 13.35128 & & \\
\hline & Mid & 38.8889 & 12.91551 & & \\
\hline & High & 47.2 & 16.14621 & & \\
\hline & $\begin{array}{l}\text { Total } \\
\text { average }\end{array}$ & 37.0636 & 13.49908 & 1.821 & .167 \\
\hline \multirow{4}{*}{$\begin{array}{l}\text { Number open } \\
\text { questions per } \\
\text { minute }\end{array}$} & Low & .1914 & .16363 & & \\
\hline & Mid & .3133 & .14665 & & \\
\hline & High & .3380 & .7362 & & \\
\hline & $\begin{array}{l}\text { Total } \\
\text { average }\end{array}$ & .2180 & .16554 & 5.912 & 0.004 \\
\hline \multirow{4}{*}{$\begin{array}{l}\text { Number of } \\
\text { reflections per } \\
\text { minute }\end{array}$} & Low & .0730 & .07179 & & \\
\hline & Mid & .1456 & .09925 & & \\
\hline & High & .2800 & .14697 & & \\
\hline & $\begin{array}{l}\text { Total } \\
\text { average }\end{array}$ & 0.0943 & 0.9367 & 19.895 & $<.001$ \\
\hline \multirow{4}{*}{$\begin{array}{l}\text { Open questions } \\
\text { as a percentage } \\
\text { of total number of } \\
\text { questions asked }\end{array}$} & Low & .3086 & .18550 & & \\
\hline & Mid & .4711 & .18569 & & \\
\hline & High & .5500 & .15116 & & \\
\hline & $\begin{array}{l}\text { Total } \\
\text { average }\end{array}$ & .3462 & .19742 & 8.994 & $<.001$ \\
\hline \multirow{4}{*}{$\begin{array}{l}\text { Complex } \\
\text { reflections as a } \\
\text { percentage of } \\
\text { total number of } \\
\text { reflections } \\
\text { offered }\end{array}$} & Low & .1155 & .23434 & & \\
\hline & Mid & .1622 & .20730 & & \\
\hline & High & .3900 & .19013 & & \\
\hline & $\begin{array}{l}\text { Total } \\
\text { average }\end{array}$ & .1390 & .23379 & 3.509 & 0.034 \\
\hline
\end{tabular}




\begin{tabular}{|l|l|l|l|l|l|}
\hline $\begin{array}{l}\text { Ratio of } \\
\text { reflections: } \\
\text { questions }\end{array}$ & Low & .1486 & .20390 & & \\
\cline { 2 - 6 } & Mid & .2072 & .10715 & & \\
\cline { 2 - 6 } & High & .4260 & .20792 & & \\
\cline { 2 - 6 } & $\begin{array}{l}\text { Total } \\
\text { average }\end{array}$ & .1708 & .19944 & 5.322 & 0.006 \\
\hline
\end{tabular}

Interaction length increased with higher level of empathy skill; the mean length of interaction was 36 minutes (low empathy skill), increasing to 39 minutes (mid empathy skill) and to 47 minutes (high empathy skill). However, one-way analysis of variance (ANOVA) found that the difference was not statistically significant.

Analysis showed that workers who communicated with a higher level of empathy skill used more open questions and reflections in their interactions than low-scoring workers.

Open questions

Workers who scored highly for empathy asked more open questions (adjusted for length of interaction; open questions per minute) and a higher proportion of questions were open questions (rather than closed questions, as a proportion of the total number of questions; ratio of open questions: total questions). There was an increase in the proportion of open questions from around a third (31\% open questions; $69 \%$ closed questions) in the lowscoring recordings to more than half (55\% open questions; $45 \%$ closed questions) in the high-scoring recordings.

\section{Reflections}

Workers who scored highly offered more reflections (total reflections, adjusted for length of interaction; total reflections per minute). In over three quarters of the low-scoring recordings there were zero reflections, whereas the minimum count of reflections in high-scoring recordings was five. Similarly, there was a difference in the nature of reflections offered, according to the level of skill. In the low-scoring sample, around 1 in 10 reflections were complex (88\% simple; $12 \%$ complex); increasing to almost 4 in 10 in the high-scoring sample (61\% simple; $39 \%$ complex). In addition high-scoring workers offered relatively more reflections, as a ratio of the number of reflections to the number of questions, within an interaction (total reflections : total questions).

A one-way analysis of variance (ANOVA) found that the difference between the means for low, mid and high scoring empathy on all behaviour count variables was significant $(p<0.05)$.

\section{Different levels of empathy skill - what do they sound like?}

What can analysis of coding sheets and transcripts tell us about the qualitative differences between high and low levels of empathy skill? All of the high scoring audios were transcribed $(n=5)$ along with a sample of the same size of the low scoring recordings $(n=5)$. Analysis identified three key themes: 'curiosity' (within which two sub-themes were identified); 'demonstrating understanding' and 'focus on feelings'. In the extracts that are included below, each conversation was between a social worker (SW) and a mother (M).

\section{Curiosity}


When practitioners communicated with a high level of curiosity, they conveyed their interest in the parent's experience. This resulted in the creation of opportunities for the parent to share their perspective and a sense of the individual family and its unique situation was uncovered. Where there was an absence of curiosity, the sense of the individual family was missing from the interaction; the voice and views of the social worker dominated.

Practitioners who scored low on the empathy scale did not demonstrate interest in the parent's perspective of a situation. Two sub-themes were identified where there was an absence of curiosity: bombardment of questions and dominating the space.

The first theme of 'bombardment of questions' was identified as low-scoring recordings were characterised by a quick succession of closed fact-finding questions. The quick turn-taking in these interactions could be described as a 'tick-box' conversation. An example of 'bombardment' was identified in a recording of a home visit that was 17 minutes long, in which the social worker asked 29 closed questions and just one open question. The closed questions were all fact-checking in nature and the replies given by the mother were limited to mainly yes or no, one-word answers. The extract below from the transcription of this recording illustrates what bombardment sounded like in practice.

SW: And were you drinking when you lived with your dad?

M: Yeah.

SW: So would you say that you ever stopped drinking to excess?

M: Not, not ... no.

SW: You've never stopped drinking to excess?

M: Well, it depends what you categorise as excess.

SW: To the point where you wouldn't be able to safely ...?

M: $\quad$ Oh l've never done that.

SW: $\quad$ But if you had to respond to something in an emergency for Richard?

M: I do ...

SW: Would you be coherent enough to be able to do that.

M: $\quad$ Yeah, always, I never get to, I never, never, never get to be one of these people that ends up going and sleeping on the sofa and passing out or whatever, never, never, I wouldn't do that.

SW: So that you're a functioning ...?

M: Yes.

SW: Okay. So you said that there's days that you can go without a drink?

M: Yeah.

SW: So have you had a drink today?

M: No. 
SW: Did you have a drink yesterday?

M: Yes.

SW: Okay, did you drink a lot yesterday?

$\mathrm{M}: \quad$ Erm ... [pause] ... mmmm, a bit.

The way the social worker focussed on gathering information about the mother's drinking, the fact finding, was of an unremitting nature, with an absence of curiosity around the mother's difficult experiences of alcohol use.

The second sub-theme within 'curiosity' in low -scoring recordings was 'dominating the space' by the practitioner alongside an absence of space for the parent to meaningfully contribute. There were recordings that could be described as a series of monologues by the practitioner. There was a sense that the practitioner's own views and perspectives took priority in the interaction.

Dominating the space was illustrated in a 25 minute recording of a meeting between a social worker and a mother of a baby discussing the plans for contact with the baby's father following separation due to domestic abuse. The social worker dominated the conversation, allowing little space for the mother to meaningfully contribute to the interaction, by sharing her views, thoughts or feelings. The number of words spoken by the social worker was almost 7 times the number of words spoken by the mother. The social worker spoke a total of 3,011 words in 89 speech turns (average no. words per turn $=33.8$ ), in contrast, the mother spoke 440 words in 88 speech turns (average no. words per turn $=5.0$ ). $40 \%$ of the mother's speech turns contained a one word answer to a closed question posed by the social worker; $80 \%$ of these one word answers were "yeah" or "yes".

The extracts below demonstrate how the social worker didn't give the mother space to answer or share what she thought or felt about the situation. Instead, the social worker projected her own view of both the situation and her perception of the mother's views.

\section{Extract 1}

SW: Are you in a new relationship by any chance? Are you still socialising with your friends and stuff?

M: Yes.

\section{Extract 2}

SW: And then at the next child protection conference, we're going to stay involved obviously and you want that don't you?

M: Yeah.

\section{Extract 3}

SW: So you're engaging really well and you'll be finished everything that you need to do by January next year, won't you?

M: Yeah. 
There are times in the recording where the social worker offered the mother an opportunity to share her view. For example, the social worker asked the open question "Why do you want us stay involved?' but didn't give the mother space to expand on her response of "Because I think that ... it's the safety thing." Instead the social worker gave her own assessment "The safety factor. Also you....", and continued with a speech turn that contained some 289 words and was followed by a one-word "Yeah" from the mother.

In contrast, high-scoring recordings were characterised by the practitioner making repeated efforts to explore a parent's perspective, demonstrating curiosity and interest in how the parent viewed issues or problems. High-scoring practitioners demonstrated their curiosity by asking a wide range of open questions.

In the example below, the social worker's demonstration of curiosity was linked to a high number of open questions which enabled exploration of the mother's views of her anxiety.

SW: So the most important reasons why you want to make the change, why is it important to you to reduce your anxiety?

M: I think obviously it wouldn't help Bobbie so if I'm anxious all the time, he's going to get off me and he's going to learn it off me.

SW: Are you thinking while he's in the womb or when he's born?

M: When he's born, if he sees me not wanting to go out or not wanting to do something, I don't want him to learn the same behaviours.

SW: Where do you think your anxiety came from?

M: I got mine from what happened.

SW: Your experiences?

M: Because I wasn't ever, as a kid I wasn't ever anxious, it was only once I got into my teens and all the mess happened that I became ...

There is a sense here that the social worker is focussed on creating the space and time for the mother to share her views; encouraging her to reflect and elaborate further about the issue of her anxiety.

\section{Demonstrating understanding}

Curiosity was linked with demonstrating understanding; the more opportunities the worker created for the parent to share their perspective, thoughts and views, the more opportunities there were for the worker to demonstrate their understanding of what the parent had to say.

Where the conversation was predominantly the practitioner talking, whether to offer their opinion or point of view, or to give the parent advice or information, or where the parent was answering questions with one-word answers, there were fewer opportunities for the parent to express themselves. This resulted in fewer opportunities for the practitioner to listen to parents, to understand them or to demonstrate this understanding to them.

In contrast, where the practitioner was curious, asking open questions and allowing time and space for the parent to share their own perspective, this created opportunities for the practitioner to listen. Practitioners with a high level of empathy skill were able to make attempts to understand the individual experiences of the individual parent and communicate 
these attempts at understanding to them. In the example below, the social worker is curious about the issue of mother's mental health and uses a cycle of open questions and reflections to develop her understanding of the 'triggers'.

SW: What do you think historically have been your trigger situations for your mood deteriorating? What sort of triggered off bouts of distress or low mood or mental health difficulties?

M: $\quad$ The partner, Trish, the drinking and then losing my kids, don't forget as well about that, it really made me go downhill, I think that was one of the worst times of my life, when they took my kids.

SW: So I guess they were the bigger triggers, losing your sister, losing your children, very difficult times in your life.

M: Social Services involved and then the sister and father losing the plot, being sectioned and ... and then the abusive relationship, well that was going on for years, everybody was telling me to get away from it, you know?

SW: So the domestic violence was more of a day to day trigger wasn't it?

M: That was every day ...

SW: That would trigger off low moods on a daily basis?

M: $\quad$ Put it this way, it was so bad that he would say to me, when my sister passed away, he said, "Why don't you kill yourself? Why are you always looking for attention?", you know what I mean? It was that kind of abuse every day thrown in my face, he was in my face and he'd wake up and have a beer and there's no way l'd be sitting there watching him getting drunk, so the best thing to do was just to get drunk and then just get worse and worse.

SW: And obviously that must have been really distressing for you, it sounds like you can make a real clear link between that abuse within the relationship, your mood deteriorating and then you drinking and self-harming, there's quite a clear link there isn't there?

The above example demonstrates how a social worker actively tried to convey their attempts to understand the parent's difficult experiences of loss, bereavement, domestic abuse, mental health, substance misuse and self-harm, going beyond what the parent explicitly stated to reflect a deeper awareness of how the issues may have been linked.

\section{Focus on feelings}

There was a difference in the extent of workers' focus on parents' feelings and emotions, both within their expression and level of curiosity, and linked with their demonstration of understanding, according to the level of empathy skill.

Recordings of workers who scored low for empathy were characterised by an absence of the practitioner exploring emotions or feelings referred to by the parent, instead asking a subsequent question or by referring to their own, professional concerns instead of the parent's as shown in the two examples below.

\section{Example 1}

M: My only concern is the court date 
SW: Are there any other concerns?

M: My only other concern is [child's] behaviour...I think she's finding it tricky

SW: In terms of our professional concerns...

\section{Example 2}

SW: Tell me what your reason is for using alcohol, what do you use alcohol for? Is it a social thing? Is it to block out something?

M: Sometimes, yeah they want me to go for grief counselling.

SW: And the grief is in regards to ...?

M: $\quad$ My mother.

SW: Let's move back, tell me your first experience of alcohol....,

The mother's expressed concerns about her child in the first example and sharing of the grief she is experiencing following the death of her mother, in the second, were not acknowledged by either social worker, there was no recognition of the emotion that had been shared or attempts to explore the feelings further.

Where attempts were made to explore the parent's perspective in low-scoring examples, they were superficial and sporadic and often returned to information-giving and directing, rather than exploring the parent's feelings further. In the example below the social worker missed an opportunity to explore the mother's feelings of reluctance to going to an appointment, instead focussing on their own reasons for attending.

SW: What about you, what do you think about the appointment?

M: I don't personally feel it's necessary, in my opinion.

SW: The reason it's in the plan is not because we feel it's going to go downhill. It's just to have the assessment, to see where we're at, to see if there is any support they can offer you.

There were also examples of missed opportunities to explore a parent's perspective, for example when a parent volunteered their thoughts or feelings on a situation.

One example where a social worker did not explore a parent's feelings, which could be regarded as almost an active dismissal of the parent's feelings, was captured in a recording in which a parent commented 'he completely controls me, it's making me really nervous'. The social worker replied 'because we've spoken about this info before I've now given this to Jane (a domestic abuse worker)'. Here, the mother shared how she was feeling but the social worker failed to respond to the emotional content, instead referring to signposting the case to another professional.

In contrast, the workers who scored highly acknowledged and demonstrated interest in the parent's emotions, as the extract below demonstrates.

M: When we had social services before, I wouldn't say things were completely and utterly normal, but it was as normal as a family could be. Then things started 
deteriorating a little bit because I lost my mum, and then I lost my dad, and that had an impact on me, and that had an impact on the boys

SW: Yeah, it's like a domino effect isn't it?

M: Yeah, and nobody knew how to communicate and express how everyone's feeling. There was just too many arguing and too many fights, you know, where the police were called. Kids carted off.

SW: So when you said normal before, because that is where we want to be back to, you said that was when children's services were involved. Was it because children's services were involved? Or was it because something else, do you think, when it was normal before?

M: I think it's because I had more family members. I had more support, I had my mum, I had my dad, I was talking to my sister at the time, so there was more support in the family home.

SW: You felt like you had more support, at that time you were talking to your sister... this was before you mum passed away, and your dad.

M: $\quad$ Yeah, there was more people that you could rely on and pick up the phone. Losing a big part of the family, losing a mum and then losing a dad and then not talking to my sister

SW: Which effectively is a loss as well. It's a different kind, but it's still a loss... let me try and summarise what you are saying and please correct me if I'm wrong. It was good previously... before all the fights started happening, before the difficult relationships, before behaviour became difficult in the home, when things use to be normal, you felt more supportive and you did have a wider support network...your support network isn't as it used to be when things were normal...

The above example shows how the social worker skilfully combined her use of open questions and thoughtful reflections to demonstrate her understanding of the mother's difficult experiences of loss and challenging relationships including a discussion and recognition of the mother's feelings.

\section{Discussion}

That empathy is important in social work is uncontested, but the concept of empathy is complex and multi-dimensional. In our study we have adopted a quantitative approach and used an Ml framework to conceptualise and measure empathy skill. We have also qualitatively explored the behavioural dimension of empathy in conversations between social workers and parents, in other words what social workers say when they communicate empathy. Such a focus makes, we hope, contributions to improving our conceptual understanding of empathy in the context of direct social work practice with potential implications for social work organisations and policy.

As noted in the introduction, there is still remarkably little empirical research that directly observes child and family social work practice and the work focussed on empathy has been largely quantitative (Forrester et al, 2017; Forrester et al, 2018). The deeper understanding provided by qualitative analysis make possible a more rounded conceptualisation of empathy. The analysis can be characterised as doing two things. First, we sampled and 
described the conversation informed by the coding approach to empathy developed within MI and applied across studies (Whittaker et al, 2016; Bostock et al, 2017; Forrester et al, 2017; Forrester et al, 2018). In this respect our findings illustrate empathy as understood within $\mathrm{Ml}$; high empathy skill is present where there is a strong focus on demonstrating an understanding of the other's point of view. Second, our analysis identified features of high empathy conversations that do not feature significantly in the coding scheme. These included curiosity about and a focus on emotional content of parents' experiences. Highlighting these features may help us to understand better what good empathy looks and sounds like, and therefore aids a better conceptual understanding of what empathy is, as a set of behaviours in child and family social work.

The study has a number of limitations. It has a focus on the behavioural dimension of empathy and does not include the emotional and cognitive dimensions. Within this behavioural dimension it features only the verbal component of empathy and not the important elements of non-verbal communication and other verbal aspects, including tone and pitch (Kraft-Todd et al, 2017). In addition, the study is an initial analysis in an underexplored area. It does not therefore analyse the many wider factors that might influence empathy, such as characteristics of the worker or family and the relationship between them or the specific situation. It provides an overview analysis of the level of empathy in these interactions, and the data did allow us to explore important relationships with wider factors such as race and gender (Lavee and Strier, 2018). Other methodological limitations include inclusion of a single observation of practice from a limited sample of workers in one organisation, so we are unable to analyse variations. We also acknowledge the need in future studies to investigate the relationship between worker and parent perception of the levels of empathy demonstrated.

But this study does represent one of the first steps to explore how empathy is communicated in child and family social work. The focus on verbal communication with qualitative analysis to complement the coding scheme also presents opportunities to inform development the coding scheme in the future. Exploration of what social workers say is a vital initial building block of our understanding of empathy and the low level of empathy skill identified in this and other studies (Forrester et al, 2017; Forrester et al, 2018) is potentially concerning. The qualitative data presented here also suggests we as a profession should be concerned about the quality of direct practice where it is characterised by an absence of curiosity about the difficult issues parents face; apparent lack of interest in the emotions and feelings of parents and little demonstration of understanding or 'trying on' (Moyers, 2005) of the parent's experiences.

Social work practice characterised by such a lack of empathy, despite agreement about its central role in the value base (Hohman, 2012); engagement with families (Forrester et al, 2008); emerging practice frameworks (McNeish, 2017), and what service users want from their social worker (Ingram, 2013), poses a challenge for our profession. It is not possible to draw conclusions about why so much practice is low in empathy. These are difficult conversations to have; perhaps we as a profession have not spent enough time on understanding how to have such conversations. It is also possible that the low level of empathy is linked to the legacy of a bureaucratic social work system (Munro and Hubbard, 2011), which placed little value on social worker demonstration of empathy. 
It is unhelpful to think of the low empathy demonstrated here as if it were a skills deficit to be corrected through training; training alone has a relatively small impact on practice skills (Forrester et al, 2018). What might be helpful is to return to the cognitive and emotional elements of empathy to understand low empathy skill. How are social workers thinking about families? And how are they feeling - about families and themselves? Is social worker vulnerability to and experience of a high level of stress (Antonopoulou et al, 2017) likely to act as an inhibitor to the cognitive and emotional processing of empathy, resulting in inability to demonstrate empathy in conversations? Are protective factors such as access to reflective supervision which promotes emotional resilience (Kinman and Grant, 2011) and is associated with higher practice skill (Bostock et al, 2017) linked to the demonstration of verbal display of high levels of empathy?

What is required now is more research to address these questions and to explore the link between empathy and outcomes (Forrester et al, in preparation), for there are practice and policy implications. Perhaps what is also required is a renewed focus on how we think about the families we work with and the emotional content of this most emotional type of work. To address the concerning lack of empathy in these interactions, perhaps we need to create organisations that are more empathic in the way they think and feel about social workers and families and the values they actively promote in order to support social workers to demonstrate empathy towards the families they work with. 


\section{References}

Allen, M., \& Roberts, L., ( 2017). Perceived acquisition, development and delivery of empathy in musculoskeletal physiotherapy encounters, Journal of Communication in Healthcare, 10, 4, pp. 304-312

Antonopoulou, P., Killian, M., and Forrester, D. (2017). Levels of stress and anxiety in child and family social work: Workers' perceptions of organizational structure, professional support and workplace opportunities in Children's Services in the UK. Children and Youth Services Review, 76, 42-50.

Bostock, L., Forrester, D., Patrizo, L., Godfrey, T., and Zonouzi, M. with Bird, H., Antonopoulou, V. and Tinarwo, M. (2017) Scaling and deepening Reclaiming Social Work model: evaluation report. London: Department for Education.

Braun, V., \& Clarke, V. (2006). Using thematic analysis in psychology. Qualitative Research in Psychology, 3, 77-101.

Bry, K., Bry, M., Hentz, E., Karlsson, H.L., Kyllönen, H., Lundkvist, M. and Wigert, H. (2016) Communication skills training enhances nurses' ability to respond with empathy to parents' emotions in a neonatal intensive care unit. Acta Paediatrica. ;105:397-406.

Dando, C. J., and Oxburgh, G. (2016). Empathy in the field: Towards a taxonomy of empathic communication in information gathering interviews with suspected sex offenders. The European Journal of Psychology Applied to Legal Context, 8(1), 27-33. doi:10.1016/j.ejpal.2015.10.001

Ferguson H. (2014). What social workers do in performing child protection work: Evidence from research into face-to-face practice. Child and Family Social Work Advance Access published March 21, 2014, 10.1111/cfs.12142

Ferguson, H. (2017). How Children Become Invisible in Child Protection Work: Findings from Research into Day-to-Day Social Work Practice, The British Journal of Social Work, Volume 47, Issue 4, 1.

Forrester, D, (2017). Outcomes in Children's Social Care, Journal of Children's Services, Vol. 12 Issue: 2-3, pp.144-157

Forrester, D., McCambridge, J., Waissbein, C., Emlyn-Jones, R. and Rollnick, S., (2008). Child risk and parental resistance: Can motivational interviewing improve the practice of child and family social workers in working with parental alcohol misuse? British Journal of Social Work, Vol. 38 No. 7, pp.1302-1319.

Forrester, D., Lynch, A., Bostock, L., Newlands, F., Preston, B. and Cary, A. (2017). Family Safeguarding Hertfordshire. London: Department for Education.

Forrester, D., Westlake, D., Killian, M., Antonopolou, V., McCann, M., Thomas, R., Waits, C., Whittaker, C. and Hutchison, D. (2018). Engaging parents and protecting children: results from a randomized trial of training in motivational interviewing for child protection social workers, Children and Youth Services Review (manuscript accepted). 
Forrester, D., et al (tbc) (in preparation), What is the relationship between worker skills and outcomes for families in child and family social work?

Gerdes, K. E. and Segal, E.A. (2011) Importance of Empathy for Social Work Practice: Integrating New Science Social Work, 56, (2).

Gerdes, K. E. and Segal, E. A. (2009). A social work model of empathy. Advances in Social Work, 1 (2), 114-127.

Grant, L. (2014). Hearts and minds: aspects of empathy and wellbeing in social work students. Social Work Education: The International Journal.

Hohman, M. (2012). Motivational interviewing in social work practice. New York, NY: Guilford.

Hohman, M., Pierce, P., \& Barnett, E. (2015). Motivational Interviewing: An evidence-based practice for improving student practice skills. Journal of Social Work Education, 51(2), 287297.

Kinman, G. and Grant, L. (2011). Predicting stress resilience in trainee social workers: the role of emotional competencies. British Journal of Social Work, 41(2): 261-275

Ingram, R. (2013). Locating Emotional Intelligence at the Heart of Social Work Practice, British Journal of Social Work, 5.

Ingram, R., \& Smith, M. (2018). Relationship-based practice: emergent themes in social work literature. (IRISS Insights; No. 41). United Kingdom: Institute for Research and Innovation in Social Services.

Kraft-Todd, G., Reinero, D. A., Kelley, J.M., Heberlein, A. S., Baer, H. and Riess, H. (2017) Empathic nonverbal behavior increases ratings of both warmth and competence in a medical context PloS one 12 (5), e0177758

Lavee E. and Strier R. (2018) Social workers' emotional labour with families in poverty: Neoliberal fatigue? Child \& Family Social Work;1-9.

Luckock, B., Hickle, K., Hampden-Thomson, G., and Dickens, R. (2017). The Islington 'Doing What Counts: Measuring What Matters' Evaluation Report Department for Education, London.

McNeish, D. with Sebba, J., Luke, N. and Rees, A. (2017). What have we learned about good social work systems and practice? Children's Social Care Innovation Programme Thematic Report 1. Oxford: Rees Centre.

Magill, M, Apodaca, T, Borsari, B, Gaume, J, Hoadley, A, Gordon, R, Tonigan, J, and Moyers, T. (2018). A meta-analysis of motivational interviewing process: Technical, relational, and conditional process models of change', Journal Of Consulting And Clinical Psychology, 86, 2, pp. 140-157

Moyers,T.B., Martin, T., Manuel, J.K., Hendrickson, S.M. and Miller, W. R. (2005). Assessing competence in the use of motivational interviewing. Journal of Substance Abuse Treatment, 28(1), 19-26. doi:10.1016/j.jsat.2004.11.001 
Munro E. (2011). The Munro Review of Child Protection: Final Report: A Child-Centred System , London TSO

Nerdrum, P. (1997). Maintenance of the effect of training in communication skills: A controlled follow-up study of level of communicated empathy. British Journal of Social Work, $27,705-722$.

Rollnick, S. and Miller, W.R. (1995) What is motivational interviewing? Behavioural and Cognitive Psychotherapy 23.04: 325-334.

Ruch G, Turney D and Ward A. (2017). Relationship based social work: getting to the heart of practice. London: Jessica Kingsley Publishers

Whittaker, C.E., Forrester, D., Killian, M. and Jones, R.K. (2016). Can we reliably measure social work communication skills? Development of a scale to measure child and family social work direct practice, International Journal of Child and Family Welfare 2016, 17 (1/2), 47-63 